\section{RSP}

http://www.rsp.fsp.usp.br/
Revista de Saúde Pública

\title{
Occupational exposure to pesticides and health symptoms among family farmers in Brazil
}

\author{
Rafael Junqueira Buralli' iD, Helena Ribeiro"I iD, Verónica Iglesias"II iD, María Teresa \\ Muñoz-Quezada' ${ }^{\mathrm{IV}}$ iD, Renata Spolti Leão ${ }^{\mathrm{V}}$ iD, Rejane Correa Marques ${ }^{\mathrm{VI}}$ iD, Milena Maria \\ Cordeiro de Almeida ${ }^{\mathrm{VII}}$ iD, Jean Remy Davée Guimarães ${ }^{\mathrm{VIII}}$ iD \\ ' Universidade de São Paulo. Faculdade de Saúde Pública. Programa de Pós-Graduação em Saúde Pública. São \\ Paulo, SP, Brasil \\ " Universidade de São Paulo. Faculdade de Saúde Pública. Departamento de Saúde Ambiental. São Paulo, SP, \\ Brasil \\ III Universidad de Chile. Escuela de Salud Pública. Departamento de Epidemiología. Santiago, Chile \\ iv Universidad Católica del Maule. Facultad de Ciencias de la Salud. Talca, Maule, Chile \\ $\checkmark$ Universidade Federal de Minas Gerais. Centro de Tecnologia em Nanomateriais e Grafeno. Belo Horizonte, \\ MG, Brasil \\ VI Universidade Federal do Rio de Janeiro, Campus Macaé. Centro Multidisciplinar - UFRJ. Macaé, RJ, Brasil \\ VII Universidade Federal da Bahia. Instituto de Ciências da Saúde. Departamento de Fisioterapia. Salvador, BA, \\ Brasil \\ VIII Universidade Federal do Rio de Janeiro. Instituto de Biofísica Carlos Chagas Filho. Rio de Janeiro, RJ, Brasil
}

\section{Correspondence: \\ Rafael Junqueira Buralli \\ Departamento de Saúde Ambiental Faculdade de Saúde Pública \\ Av. Dr. Arnaldo, 715 01246-904 São Paulo, SP, Brasil \\ E-mail: rafael.buralli@gmail.com}

Received: Dec 12, 2019

Approved: Apr 9, 2020

How to cite: Buralli RJ

Ribeiro H, Iglesias V, MuñozQuezada MT, Leão RS, Marques $\mathrm{RC}$, et al. Occupational exposure to pesticides and health symptoms among family farmers in Brazil. Rev Saude Publica. 2020;54:133.

Copyright: This is an open-access article distributed under the terms of the Creative Commons Attribution License, which permits unrestricted use, distribution, and reproduction in any medium, provided that the original author and source are credited.

\section{ABSTRACT}

OBJECTIVE: To explore the association of occupational pesticide exposure with acute and mental health symptoms.

METHODS: Cross-sectional survey carried out with 78 Brazilian family farmers, who were pesticide applicators and helpers conveniently selected. Symptoms and exposure data were collected by interviews, and mental health outcomes by the Self-Reporting Questionnaire. Blood samples were analyzed to assess cholinesterase levels. Exposure indicators and symptoms were compared between applicators and helpers, and Poisson regression was performed to estimate prevalence ratios.

RESULTS: Farmers reported exposure to multiple pesticides from early ages; they worked without safety training, technical support, and full protective equipment, and they had a high prevalence of acute and mental health symptoms (e.g., headache, mucosal irritation, tachycardia, and depressive signs). Applicators had more cholinesterase changes than helpers, but less symptoms. Helpers used less personal protection and had significantly higher prevalence ratio of headache, dyspnea, wheezing, cough, poor digestion, tiredness, and feeling worthless, after adjustment.

CONCLUSIONS: Acute and mental health symptoms were observed, both among farmers and helpers. Thus, surveillance actions must be reinforced in Brazil, technical support and safety training improved, focused on applicators and helpers, who are occupationally and environmentally exposed to pesticides. Agricultural practices of these groups with less pesticide use should receive incentive.

DESCRIPTORS: Farmers. Pesticide Exposure. Mental Disorders, epidemiology. Occupational Health. 


\section{INTRODUCTION}

Excessive and unsafe use of pesticides represents a serious risk to human health, environment, and quality of food. About 25 million people experience unintentional pesticide poisoning yearly worldwide ${ }^{1}$, resulting in 200,000 deaths, mainly affecting low- and middle-income countries (LMIC) ${ }^{2}$. In LMIC, the occupational exposure to pesticides has been associated with gastrointestinal, musculoskeletal, respiratory, allergic, and nervous effects $^{3-6}$, and common mental disorders (CMD) such as depression, anxiety, and suicide ${ }^{7-9}$. However, these adverse effects are not restricted to LMIC, and occupational exposure to pesticides was associated with health outcomes in high-income countries such as the USA, England, South Korea, and Spain ${ }^{10,11}$.

Between 2010 and 2015, more than 600,000 pesticide poisoning cases and 2,074 deaths occurred in Brazil ${ }^{12}$, but the cases are vastly underreported by national information systems. It is estimated that for every registered case there are 50 unregistered ones $^{13}$. Mental illness is a major public health concern in terms of lost health and burden of disease, and its symptoms are often overlooked by health services ${ }^{14}$. Depression and anxiety affect, respectively, $5.8 \%$ and $9.3 \%$ of the Brazilian population, more than $4.4 \%$ and $3.6 \%$ affected worldwide ${ }^{15}$.

Farmers from LMIC, mostly located in tropical areas with easy pest proliferation, tend to be more exposed to pesticides due to the lack of safety regulation, surveillance and training, increased use of highly toxic chemicals, low risk awareness, misuse of personal protective equipment (PPE), and careless handling and pulverization ${ }^{2,4,5}$. Studies conducted in Brazil showed that farmers commonly use complex mixtures of pesticides without precautionary measures, which could potentially reduce exposure and protect their health ${ }^{16-18}$.

Brazil is a world's leading agricultural producer, and the largest consumer of pesticides since 2008 , trading highly toxic chemicals banned in many countries ${ }^{13}$. Cholinesterase-inhibitor pesticides, such as organophosphates (OP) and carbamates (CM), represent an important risk for human health and are considered the main responsible for pesticide poisoning in $\mathrm{LMIC}^{4}$.

Family farming is the primary income source for $40 \%$ of the active population in Brazil and for $90 \%$ of municipalities with fewer than 20,000 inhabitants $^{19}$.

Although studies conducted in Brazil had explored the health effect of pesticide use $e^{8,918,20}$, many regions and crops are still underrepresented, and mental health and tomato growers were not studied recently. Therefore, this study aims to explore the association between pesticide exposure and the prevalence of self-reported acute and mental health symptoms among family farmers in São José de Ubá, state of Rio de Janeiro.

\section{METHODS}

\section{Study Area and Sample}

This cross-sectional study was conducted in July and August 2014, at the end of the crop season, in São José de Ubá (SJU), located in a mountainous region in the Northwest of the state of Rio de Janeiro, Brazil (Figure). SJU is a small municipality of 7,000 inhabitants, where $55 \%$ live in the rural area, $16 \%$ has formal employment, and $40 \%$ have a monthly per capita income equivalent to $\$ 100$ US dollars or less than half the national minimum wage $^{19}$. SJU is one of the largest tomato producers in Brazil, and the municipality income depends on smallholder family farming ${ }^{19}$. Tomato cultivation demands an intensive care for pest control, commonly based on the use of large amounts of pesticides ${ }^{13}$. Between 2007 and 2017, the yearly tomato production in SJU ranged between 21,000 and 32,000 tons ${ }^{19}$. Previous studies revealed soil degradation and water contamination as a consequence of intensive farming and livestock practices ${ }^{21}$. 

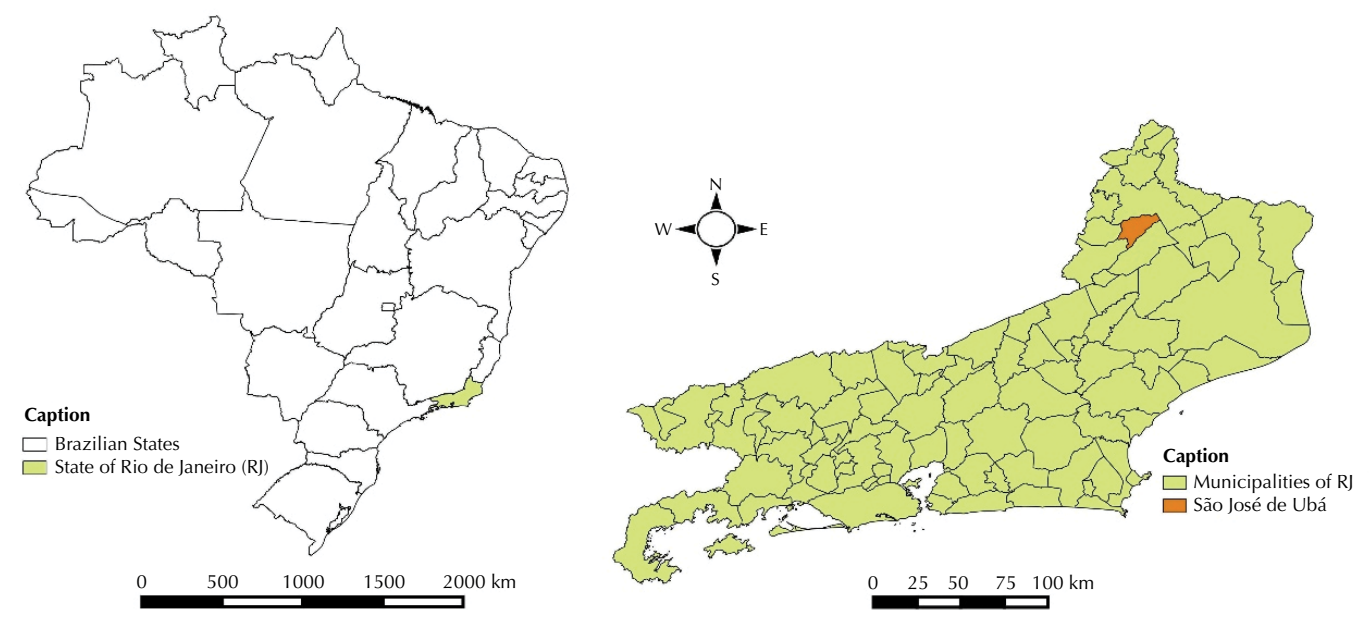

Figure. Map of study location, São José de Ubá, State of Rio de Janeiro, Brazil.

The study sample was composed of 78 family farmers, older than 18 years, recruited sequentially by convenience in agricultural areas of SJU with word-of-mouth of residents and stakeholders (snowball sampling). Almost all (95\%) individuals recruited agreed to participate in the study, and participants represented about $11 \%$ of tomato growers in SJU. The final sample size was delimited by the time and budget constraints of the project.

This study is part of a broader project assessing human health risk by pesticides and metals exposure in SJU, and the study methodology ${ }^{21}$ and pulmonary function impairment ${ }^{22}$ were discussed elsewhere. The study protocol was approved by the Ethical Board of the Hospital Universitário Clementino Fraga Filho of the Universidade Federal do Rio de Janeiro, and all participants provided written informed consent. Test results were delivered individually, and guidance on health protection provided. Individuals with significant outcomes were referred to the municipal healthcare service.

Based on observational visits and self-declared cultivation tasks, participants $(\mathrm{n}=78)$ were divided into two groups as a proxy of exposure: a) applicators ( $n=42)$, who were daily involved in all crop activities, including pesticide handling and spraying; and b) current or former helpers ( $\mathrm{n}=36$ ), who were farmer's relatives performing additional crop-related tasks, but not pesticide spraying.

Individual interviews based on questionnaire were carried out at participant's households, neighborhood schools and healthcare units to ease community engagement and assimilate the local culture. Socioeconomic and demographic data such as age, gender, marital status, body mass index (BMI), educational level, smoking habits, and alcohol consumption were obtained. Monthly family income was estimated based on the Brazilian minimum wage ( $\mathrm{R} \$ 998$ in 2019), which was equivalent to approximately US\$ 240 and now is around US\$ 200.

\section{Exposure Assessment}

Participants were asked about their current and previous pesticide exposure, including: duration of work with pesticides, age of first exposure working or helping at crops, home distance from crop areas, use of recommended PPE (cloth mask, visor, hat, gloves, boots, and overall), types of pesticide frequently used, previous training and technical support received, residential exposure to pesticides (either by use for pest control or by contact with contaminated clothes and equipment), and poisoning history. Safety practices (e.g. eating at the field, washing hands, and showering after crop activities) were also investigated. 
Some farmers refused to participate in blood tests or had insufficient samples. Samples from 70 participants were collected by qualified health personnel to evaluate acetylcholinesterase (AChE) and butyrylcholinesterase (BChE) inhibition, which are respectively biomarkers of chronic and acute exposure to OP and CM pesticides ${ }^{13}$. The AChE and BChE biomarkers are useful for an initial screening of pesticide poisoning, although they have low specificity and sensitivity, and they are not effective to assess other chemical classes of pesticides ${ }^{17}$.

Measurements were performed by the Centro de Estudos da Saúde do Trabalhador e Ecologia Humana (CESTEH/FIOCRUZ) by the modified Ellman method ${ }^{23}$, in which reference values were defined as $0.56 \mathrm{mmol} / \mathrm{min} / \mathrm{mg}$ for AChE for both genders, and 2.29 for BChE for men and $1.61 \mathrm{mmol} / \mathrm{min} / \mathrm{mg}$ for women. Values above these were considered normal.

\section{Self-Reported Symptoms and Mental Health Assessment}

Twenty-three acute symptoms previously associated with pesticide poisoning were presented to the participants, who were asked to confirm whether they regularly had them or not. Prevalence of probable CMD was assessed by the Self-Reporting Questionnaire (SRQ-20), proposed by WHO as a low-cost and easy tool for psychiatric screening, and it is recommended for community studies and basic care. The questionnaire has 20 binaries questions (yes/no) about depressive and anxiety signs, reduced vital energy, and somatic symptoms. It was validated in Brazil with good internal consistency ${ }^{24}$, high sensitivity (83\%) and specificity $(80 \%)^{25}$, and the standard cutoff was set as six or more positive answers for men and eight or more for women ${ }^{14}$.

Table 1. Sociodemographic characteristics among family farmers in São José de Ubá, Brazil, divided by occupational groups. Crop season, 2014.

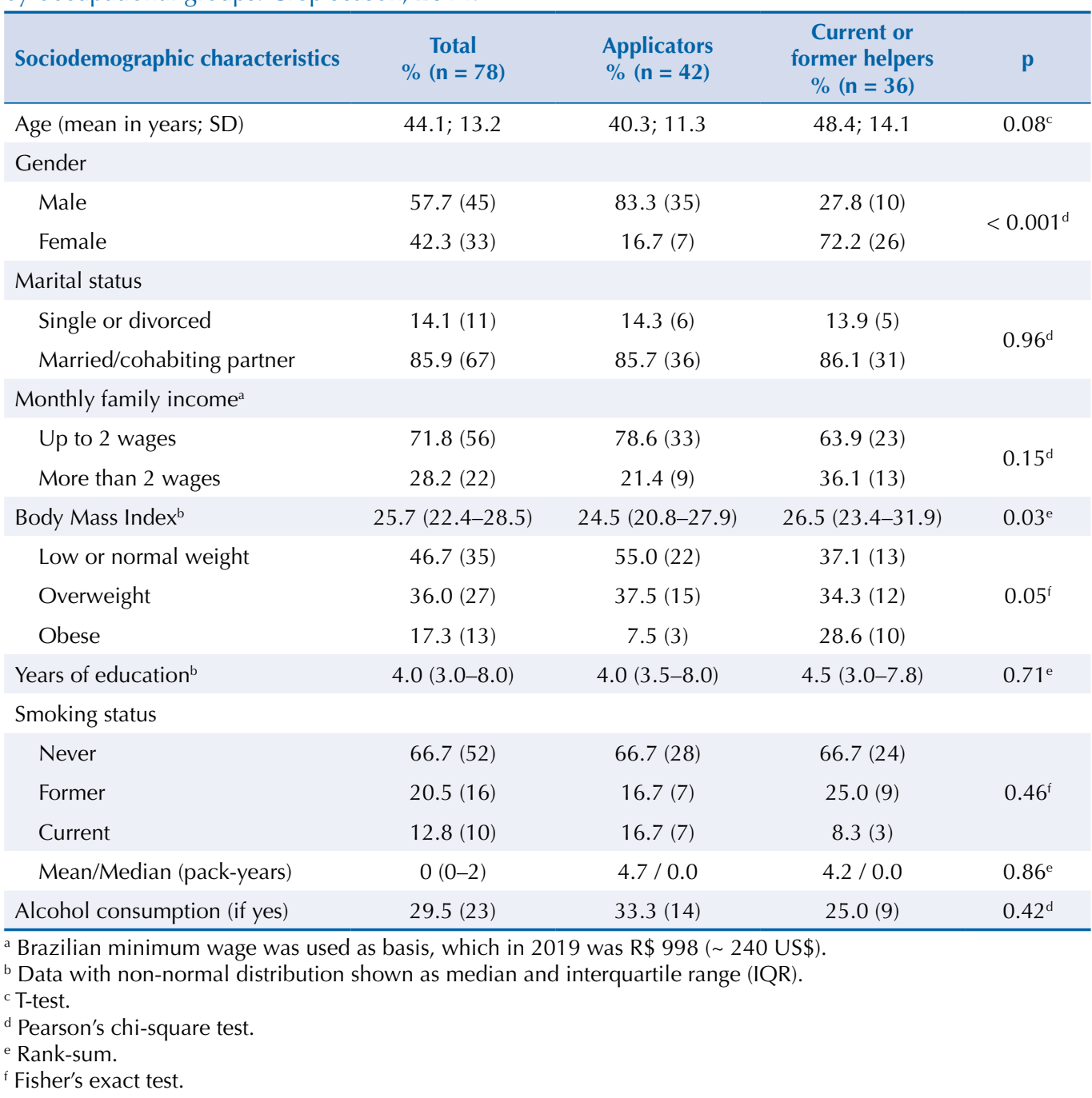




\section{Statistical Analysis}

The prevalence of sociodemographic and pesticide exposure data was compared between occupational groups (pesticide applicators versus helpers). Data with normal distribution were presented as mean and standard deviation (SD), and with non-normal distribution as median and interquartile range (IQR 25-75\%). Pearson's chi-square test was used to compare categorical variables, and Fisher's exact test was used for variables with less than five observations. Continuous variables with normal distribution were compared among groups by T-test, and with non-normal distribution by Rank-sum. Cholinesterase activity was compared with the reference values and among groups ${ }^{23}$. The prevalence of each acute and mental health symptom was compared between applicators and helpers, and possible associations tested by Poisson regression with robust variance, adjusted by potential confounders, namely age, BMI, smoking habit, gender, and alcohol consumption. Family income was similar among groups; thus it was not included in the analysis. Statistical analysis was performed using Stata 14 (Stata Corp., College Station, TX, USA) and SPSS 23 (IBM Corp., Chicago, IL, USA). $p$-values $<0.05$ were considered significant.

Table 2. Pesticide exposure characteristics among family farmers in São José de Ubá, Brazil, divided by occupational groups. Crop season, 2014.

\begin{tabular}{|c|c|c|c|c|}
\hline Exposure characteristics & \begin{tabular}{l}
\multicolumn{1}{c}{ Total } \\
$\%(n=78)$
\end{tabular} & $\begin{array}{c}\text { Applicators } \\
\%(n=42)\end{array}$ & $\begin{array}{c}\text { Current or } \\
\text { former helpers } \\
\%(n=36)\end{array}$ & $\mathbf{p}$ \\
\hline Years of work with crops (mean \pm SD) & $27.0 \pm 14.3$ & $27.0 \pm 12.4$ & $27.1 \pm 16.4$ & $0.92^{\mathrm{d}}$ \\
\hline \multicolumn{5}{|l|}{ Age of first exposure at crop } \\
\hline Up to 12 years old & $50.0(39)$ & $59.5(25)$ & $38.9(14)$ & \multirow{3}{*}{$0.08^{\mathrm{e}}$} \\
\hline Between $13-17$ years old & $29.5(23)$ & $28.6(12)$ & $30.6(11)$ & \\
\hline More than 18 years old & $20.5(16)$ & $11.9(5)$ & $30.6(11)$ & \\
\hline Home exposure (if yes) & $87.2(68)$ & $81.0(34)$ & $94.4(34)$ & $0.08^{\mathrm{e}}$ \\
\hline \multicolumn{5}{|l|}{ Residential distance from crop } \\
\hline Up to $1 \mathrm{~km}$ & $84.6(66)$ & $85.7(36)$ & $83.3(30)$ & \multirow{2}{*}{$0.77^{\mathrm{e}}$} \\
\hline More than $1 \mathrm{~km}$ & $15.4(12)$ & $14.3(6)$ & $16.7(6)$ & \\
\hline \multicolumn{5}{|l|}{ Use of PPE ${ }^{a}$} \\
\hline Use of any PPE & $67.9(53)$ & $95.2(40)$ & $36.1(13)$ & $<0.001^{\mathrm{e}}$ \\
\hline Use of cloth mask & $50.0(39)$ & $78.6(33)$ & $16.7(6)$ & $<0.001^{\mathrm{e}}$ \\
\hline Use of visor & $14.1(11)$ & $21.4(9)$ & $5.6(2)$ & $0.06^{f}$ \\
\hline Use of hat & $37.2(29)$ & $59.5(25)$ & $11.1(4)$ & $<0.001^{\mathrm{f}}$ \\
\hline Use of gloves & $52.6(41)$ & $76.2(32)$ & $25.0(9)$ & $<0.001^{\mathrm{e}}$ \\
\hline Use of boots & $53.8(42)$ & $76.2(32)$ & $27.8(10)$ & $<0.001^{\mathrm{e}}$ \\
\hline Use of overcoat & $39.7(31)$ & $59.5(25)$ & $16.7(6)$ & $<0.001^{\mathrm{e}}$ \\
\hline Previous poisoning (if yes) & $17.9(14)$ & $16.7(7)$ & $19.4(7)$ & $0.75^{\mathrm{e}}$ \\
\hline Received training/technical support & $14.1(11)$ & $19.0(8)$ & $8.3(3)$ & $0.21^{f}$ \\
\hline Washes hands after working at crop & $80.8(63)$ & $88.1(37)$ & $72.2(26)$ & $0.08^{\mathrm{e}}$ \\
\hline Takes shower after working at crop & $60.3(47)$ & $69.0(29)$ & $50.0(18)$ & $0.09^{\mathrm{e}}$ \\
\hline Consumes food and water in the field & $91.0(71)$ & $95.2(40)$ & $86.1(31)$ & $0.16^{\mathrm{e}}$ \\
\hline \multicolumn{5}{|l|}{ Cholinesterase tests $^{\mathrm{b}}$} \\
\hline $\mathrm{AChE}($ mean $\pm \mathrm{SD})$ & $1.29 \pm 0.42$ & $1.23 \pm 0.44$ & $1.35 \pm 0.38$ & $0.25^{\mathrm{d}}$ \\
\hline $\mathrm{BChE}($ mean $\pm \mathrm{SD})$ & $3.30 \pm 1.06$ & $3.16 \pm 1.09$ & $3.48 \pm 1.02$ & $0.21^{\mathrm{d}}$ \\
\hline $\mathrm{BChE}$ below the $\mathrm{RV}^{\mathrm{c}}$ & $20.0(14)$ & $28.2(11)$ & $9.7(3)$ & $0.07^{f}$ \\
\hline
\end{tabular}

a PPE: Personal protective equipment; ${ }^{\mathrm{b}} n=70$ samples, and values are expressed in $\mathrm{mmol} / \mathrm{min} / \mathrm{mg}$;

c RV: reference values, for $\mathrm{AChE}=0.56$ (for both genders), and $\mathrm{BChE}=2.29 \mathrm{mmol} / \mathrm{min} / \mathrm{mg}$ for $\mathrm{men}$ and

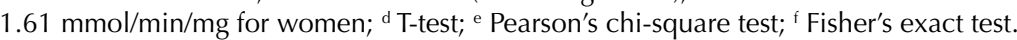




\section{RESULTS}

Most participants were married, had low educational level and family income, they had never smoked or were former smokers, and did not consume alcohol. Most applicators were men (83.3\%), had a mean age of 40.3 years, and worked with crops for 27 years. Current or former helpers were mostly women (72.2\%), had a mean age of 48.4 years, worked or helped in crop activities for 27 years, and had a significantly higher BMI (Table 1).

Most participants started to help in crop activities at early ages, lived up to $1 \mathrm{~km}$ from crop areas, never had technical support or safety training to work with pesticides, and they were domestically exposed to pesticides by using them for household pest control or having contact with contaminated clothes or equipment. Most applicators directly handled or sprayed pesticides for 1-3 days (85.7\%) or 4-7 days (11.9\%) per week during the crop season, while helpers never or rarely handled pesticides. Applicators affirmed to use significantly more PPE than helpers (although not complete), and considered visors hot and uncomfortable, thus they did not use them often (Table 2).

All participants had normal AChE values (above the reference level), while 11 applicators (28\%) and three helpers (10\%) presented inhibited $\mathrm{BChE}$ (below the reference level), without significant differences between groups. Applicators presented lower mean values for AChE and BChE, but they were not statistically significant (Table 2).

Table 3. Prevalence of self-reported acute symptoms and prevalence ratio (PR) of occupational group during the crop-season (2014) in São José de Ubá, Brazil.

\begin{tabular}{|c|c|c|c|c|c|c|}
\hline \multirow{2}{*}{ Acute symptoms } & \multirow{2}{*}{$\begin{array}{c}\text { Applicators } \\
\%(n=42)\end{array}$} & \multirow{2}{*}{$\begin{array}{l}\text { Helpers } \\
\%(n=36)\end{array}$} & \multicolumn{2}{|c|}{ Crude model } & \multicolumn{2}{|c|}{ Adjusted model $^{b}$} \\
\hline & & & $\mathbf{P R}^{\mathbf{a}}$ & $95 \% \mathrm{Cl}$ & $\mathbf{P R}^{\mathbf{a}}$ & $95 \% \mathrm{Cl}$ \\
\hline Headache & $31.0(13)$ & $50.0(18)$ & 1.62 & $0.92-2.83$ & 2.09 & $1.09-4.01^{\mathrm{d}}$ \\
\hline Dizziness & $26.2(11)$ & $33.3(12)$ & 1.27 & $0.64-2.54$ & 0.83 & $0.35-2.01$ \\
\hline Tremors & $7.1(3)$ & $22.2(8)$ & 3.11 & $0.88-10.95$ & 2.69 & $0.73-9.94$ \\
\hline Tingling in upper limbs & $7.1(3)$ & $38.9(14)$ & 5.44 & $1.69-17.58^{\mathrm{d}}$ & 3.12 & $0.77-12.66$ \\
\hline Tingling in lower limbs & $4.8(2)$ & $33.3(12)$ & 7.00 & $1.66-29.50^{d}$ & 3.33 & $0.57-19.28$ \\
\hline Muscle weakness & $16.7(7)$ & $27.8(10)$ & 1.67 & $0.70-3.95$ & 0.70 & $0.24-2.04$ \\
\hline Lower limbs fatigue & $21.4(9)$ & $47.2(17)$ & 2.20 & $1.12-4.34^{\mathrm{d}}$ & 1.05 & $0.48-2.26$ \\
\hline Blurred vision & $31.0(13)$ & $27.8(10)$ & 0.90 & $0.45-1.80$ & 0.83 & $0.31-2.20$ \\
\hline Photophobia & $14.3(6)$ & $30.6(11)$ & 2.14 & $0.87-5.24$ & 2.47 & $0.94-6.46$ \\
\hline Cramps & $16.7(7)$ & $38.9(14)$ & 2.33 & $1.05-5.17^{\mathrm{d}}$ & 1.71 & $0.58-5.06$ \\
\hline Tinnitus & $21.4(9)$ & $22.2(8)$ & 1.04 & $0.44-2.41$ & 1.22 & $0.51-2.93$ \\
\hline Excessive salivation & $14.3(6)$ & $11.1(4)$ & 0.78 & $0.24-2.56$ & 0.95 & $0.29-3.19$ \\
\hline Nausea/vomiting & $19.0(8)$ & $19.4(7)$ & 1.02 & $0.41-2.55$ & 0.99 & $0.35-2.76$ \\
\hline Lack of appetite & $7.1(3)$ & $16.7(6)$ & 2.33 & $0.62-8.74$ & 1.06 & $0.26-4.38$ \\
\hline Stomach pain & $19.0(8)$ & $38.9(14)$ & 2.04 & $0.96-4.33$ & 1.13 & $0.51-2.51$ \\
\hline Skin irritation & $16.7(7)$ & $25.0(9)$ & 1.50 & $0.62-3.64$ & 0.52 & $0.18-1.49$ \\
\hline Mucosal irritation & $38.1(16)$ & $44.4(16)$ & 1.17 & $0.68-1.99$ & 0.80 & $0.41-1.55$ \\
\hline Tachycardia & $38.1(16)$ & $33.3(12)$ & 0.88 & $0.48-1.60$ & 0.70 & $0.32-1.55$ \\
\hline Palpitation & $28.6(12)$ & $38.9(14)$ & 1.36 & $0.72-2.56$ & 0.91 & $0.39-2.11$ \\
\hline Excessive sweating & $9.5(4)$ & $13.9(5)$ & 1.46 & $0.42-5.07$ & 0.83 & $0.17-4.15$ \\
\hline Dyspnea & $11.9(5)$ & $38.9(14)$ & 3.27 & $1.30-8.24^{\mathrm{d}}$ & 3.83 & $1.54-9.52^{\mathrm{d}}$ \\
\hline Wheezing & $2.4(1)$ & $27.8(10)$ & 11.67 & $1.55-87.93^{d}$ & 16.07 & $2.37-108.75^{\mathrm{d}}$ \\
\hline Cough & $16.7(7)$ & $30.6(11)$ & 1.83 & $0.79-4.26$ & 2.64 & $1.07-6.50^{\mathrm{d}}$ \\
\hline Total of symptoms ${ }^{c}$ & $3.5(1.0-6.0)$ & $6.5(3.3-10.5)$ & 1.70 & $1.19-2.42^{\mathrm{d}}$ & 1.32 & $0.86-2.03$ \\
\hline
\end{tabular}

a Prevalence ratio: helpers versus applicators as reference group; ${ }^{\mathrm{b}}$ Adjusted by age, BMI, and smoking habits (pack-years), all continuous variables, and gender (male $=1$, female $=2$ ) and alcohol consumption (yes/no); ${ }^{c}$ Sum of symptoms reported by each subject, presented as median and IQR interquartile range $(25-75 \%) ;{ }^{d}$ Data with significant $p$-Value $(\leq 0.05)$. 
Regarding the products used, 49 pesticides from 31 chemical groups were cited, mainly OP pesticides such as Acephate and Chlorpyrifos, CM pesticides such as Mancozeb and Methomyl, pyrethroids such as Lambda-Cyhalothrin and Deltamethrin, and also nitriles, diamides, neonicotinoids, avermectins, and benzimidazole. Most of these chemicals are classified as extremely and highly toxic to humans ${ }^{26}$. About $30 \%$ of applicators did not know which pesticides they were applying because someone else does the mixture and they only apply. Glyphosate and Paraquat were cited by $35 \%$ and $17 \%$, respectively, but they are prohibited for tomato cultivation in Brazil ${ }^{13}$. The extremely toxics Chlorpyrifos and 2,4-D are forbidden for tomato crops in Brazil, and the highly toxic Endosulfan was already banned, but it was also mentioned.

Overall, only $11.5 \%$ of participants did not report any acute symptom, while $27 \%$ had between one and three, $45 \%$ between four and nine, and $16.7 \%$ more than 10 symptoms (out of 23). The symptoms most commonly reported were: mucosal irritation (41\%), headache (40\%), tachycardia (36\%), lower limbs fatigue and palpitation (33\%), dizziness and blurred vision (29\%), stomach pain (28\%), and cramps (27\%) (Table 3).

Generally, symptoms were more prevalent among helpers than applicators, except for blurred vision, excessive salivation, and tachycardia. Significant differences among occupational

Table 4. Prevalence of affirmative answers of the Self-Reporting Questionnaire (SRQ-20), probable common mental disorder, and prevalence ratio (PR) among smallholder family farmers, divided by occupational group during the crop-season (2014) in São José de Ubá, Brazil.

\begin{tabular}{|c|c|c|c|c|c|c|}
\hline \multirow[b]{2}{*}{ SRQ-20 - Affirmative answers } & \multicolumn{4}{|c|}{ Prevalence (Crude model) } & \multicolumn{2}{|c|}{ Adjusted model $^{b}$} \\
\hline & $\begin{array}{l}\text { Applicators } \\
\%(n=42)\end{array}$ & $\begin{array}{c}\text { Helpers } \\
\%(n=36)\end{array}$ & $\mathbf{P R}^{\mathbf{a}}$ & $95 \% \mathrm{Cl}$ & $\mathbf{P R}^{\mathbf{a}}$ & $95 \% \mathrm{Cl}$ \\
\hline \multicolumn{7}{|l|}{ Depressive/Anxious signs } \\
\hline Feel nervous, tense or worried & $54.8(23)$ & $69.4(25)$ & 1.27 & $0.89-1.80$ & 1.28 & $0.85-1.93$ \\
\hline Easily frightened & $33.3(14)$ & $50.0(18)$ & 1.50 & $0.87-2.58$ & 1.74 & $0.99-3.07$ \\
\hline Feel unhappy & $14.3(6)$ & $30.6(11)$ & 2.14 & $0.87-5.24$ & 1.76 & $0.58-5.31$ \\
\hline Cry more than usual & $9.5(4)$ & $25.0(9)$ & 2.63 & $0.88-7.87$ & 1.90 & $0.62-5.76$ \\
\hline \multicolumn{7}{|l|}{ Somatic symptoms } \\
\hline Often have headaches & $28.6(12)$ & $38.9(14)$ & 1.36 & $0.72-2.56$ & 1.53 & $0.69-3.42$ \\
\hline Poor sleep & $26.2(11)$ & $55.6(20)$ & 2.12 & $1.18-3.82^{\mathrm{d}}$ & 1.08 & $0.53-2.23$ \\
\hline Uncomfortable stomach feelings & $21.4(9)$ & $27.8(10)$ & 1.30 & $0.59-2.85$ & 0.99 & $0.41-2.35$ \\
\hline Poor digestion & $2.4(1)$ & $16.7(6)$ & 7.00 & $0.87-56.20$ & 7.85 & $1.17-52.89^{\mathrm{d}}$ \\
\hline Poor appetite & $9.5(4)$ & $22.2(8)$ & 2.33 & $0.76-7.16$ & 1.11 & $0.37-3.34$ \\
\hline Hands shake & $21.4(9)$ & $25.0(9)$ & 1.17 & $0.52-2.64$ & 1.14 & $0.43-2.99$ \\
\hline \multicolumn{7}{|l|}{ Reduced vital energy } \\
\hline Feeling easily tired & $16.7(7)$ & $47.2(17)$ & 2.83 & $1.32-6.08^{\mathrm{d}}$ & 3.20 & $1.33-7.66^{\mathrm{d}}$ \\
\hline Difficulty in making decisions & $21.4(9)$ & $30.6(11)$ & 1.43 & $0.66-3.06$ & 0.69 & $0.27-1.79$ \\
\hline Difficulty in enjoying daily activities & $11.9(5)$ & $25.0(9)$ & 2.10 & $0.77-5.74$ & 1.11 & $0.38-3.29$ \\
\hline Daily work suffering & $38.1(16)$ & $16.7(6)$ & 0.44 & $0.19-1.00^{\mathrm{d}}$ & 0.48 & $0.21-1.10$ \\
\hline Feeling tired all the time & $19.0(8)$ & $36.1(13)$ & 1.90 & $0.88-4.07$ & 1.86 & $0.76-4.54$ \\
\hline Trouble thinking clearly & $21.4(9)$ & $33.3(12)$ & 1.56 & $0.74-3.28$ & 1.18 & $0.56-2.50$ \\
\hline \multicolumn{7}{|l|}{ Depressive thoughts } \\
\hline Unable to play a useful part & $7.1(3)$ & $25.0(9)$ & 3.50 & $1.02-12.05^{\mathrm{d}}$ & 2.35 & $0.68-8.10$ \\
\hline Lost interest in things & $11.9(5)$ & $25.0(9)$ & 2.10 & $0.77-5.74$ & 1.54 & $0.43-5.54$ \\
\hline Thought of ending your life & $7.1(3)$ & $16.7(6)$ & 2.33 & $0.62-8.74$ & 1.60 & $0.41-6.15$ \\
\hline Feeling worthless & $4.8(2)$ & $36.1(13)$ & 7.58 & $1.82-31.68^{\mathrm{d}}$ & 7.23 & $1.69-31.04^{\mathrm{d}}$ \\
\hline Probable $\mathrm{CMD}^{\mathrm{c}}$ & $23.8(10)$ & $44.4(16)$ & 1.87 & $0.97-3.60$ & 1.85 & $0.92-3.72$ \\
\hline
\end{tabular}

a Prevalence ratio: helpers versus applicators as reference group; ${ }^{\mathrm{b}}$ Adjusted by age, BMI, and smoking habits (pack-years), all continuous variables, and gender ( male $=1$, female $=2$ ) and alcohol consumption (yes/no); ${ }^{c}$ Probable common mental disorder $(\mathrm{CMD})=$ individuals above the cutoff level (six or more positive answers for men and eight or more for women); ${ }^{d}$ Data with significant $p$-value $(\leq 0.05)$. 
groups were found for tingling in upper and lower limbs, fatigue, cramps, dyspnea, wheezing, and total of acute symptoms, all with higher prevalence ratios among helpers. After adjusted for potential confounders, helpers showed significantly higher prevalence ratios than applicators for headache ( $\mathrm{PR}=2.09$; 95\% CI 1.09-4.01), dyspnea ( $\mathrm{PR}=3.83$; 95\%CI 1.54-9.52), wheezing ( $\mathrm{PR}=16.07$; 95\% CI 2.37-108.75), and cough ( $\mathrm{PR}=2.64 ; 95 \% \mathrm{CI} 1.07-6.50)$. Moreover, a prevalence higher than $30 \%$ was observed for dizziness, photophobia, stomach pain, palpitation, and cough among helpers, and for headache, mucosal irritation, and tachycardia in both groups, although without significant differences between groups (Table 3).

Helpers showed higher prevalence of all mental health symptoms in the SRQ-20, except for daily work suffering. Statistically significant differences in PR were observed between occupational groups for poor sleep, feeling easily tired, unable to play a useful part, and feeling worthless, all with higher PR among helpers, while daily work suffering was higher among applicators. After adjustment for age, BMI, smoking habit, gender and alcohol consumption, higher PR among helpers was observed for poor digestion (PR $=7.85$; 95\%CI 1.17-52.89), feeling easily tired ( $\mathrm{PR}=3.20$; 95\% CI 1.33-7.66), and feeling worthless ( $\mathrm{PR}=7.23$; 95\%CI 1.69-31.04). Furthermore, some mental health symptoms had a prevalence as high as $50 \%$ or $30 \%$, but without significant differences between groups (Table 4).

\section{DISCUSSION}

Our study shows that smallholder family farmers in SJU were occupationally and environmentally exposed to pesticides from an early age, lived near crops, worked without safety training, technical support and full recommended PPE, and had a considerable number of acute and mental health symptoms. First, our hypothesis was that applicators are more exposed to pesticides and have more symptoms than helpers who assist in crop activities; however, most symptoms had higher prevalence among current and former helpers, even after adjusting for possible confounders, including gender. An explanation may be that helpers are also very exposed to pesticides due to their higher residential exposure, lower training, and involvement in re-entry tasks on the same day or day after spraying using less PPE. Selection bias could have occurred when considering the farmers who stopped working because they felt ill as former helpers, though it could also be due to residual uncontrolled confounders. Compared with helpers, participants in the pesticide applicators group were mostly younger men who started to work in agriculture at an earlier age and handled multiple pesticides about three times a week, had a higher duration of exposure at crops, but lower residential exposure.

The symptomatology presented in this study must be interpreted with caution due to the small sample size, although our findings are supported by previous studies conducted in other LMIC, and also high-income countries. In our study, farmworkers performing re-entry activities were less trained, used fewer PPE, performed less hygienic practices, and showed more symptoms than pesticide applicators from Ethiopia ${ }^{6}$ and Chile ${ }^{4}$.

Moreover, participants in our study had less safety guidance, used less protection and had higher prevalence of symptoms than both pesticide applicators and non-applicators from Zanzibar ${ }^{27}$. On the other hand, coffee farmers from Dominican Republic exposed to multiple pesticides without using PPE (e.g., only $13 \%$ used masks and gloves) had a higher prevalence of all symptoms than participants in our study 5 . These findings emphasize the role of protection equipment and technical support in poisoning prevention.

High-income countries have overcome the acute pesticide poisonings and are more concerned about chronic effects and long-term exposure. But acute and chronic poisonings still persist and are growing problems for $\mathrm{LMIC}^{6}$. According to the WHO, an acute pesticide poisoning must present clear signs of exposure, temporal cause-effect relationship, and at least three symptoms compatible with the exposure ${ }^{28}$. In our study, participants were asked to confirm which symptoms they regularly have, so we cannot ensure temporality; however, 
most individuals were continuously exposed, and $60 \%$ of them had more than four acute symptoms suggestive of pesticide poisoning.

Regarding mental health, helpers in SJU had higher prevalence than applicators in all questions about depressive and anxiety symptoms, and nearly twice as high CMD prevalence (44\% versus $24 \%$ ). Other studies assessed the CMD of Brazilian farmers with SRQ-20, and results vary widely. A study found a CMD prevalence of $34 \%$, being significantly higher for women (40\%) than men $(26 \%)^{7}$. Another study with tobacco farmers found a CMD prevalence of $12 \%$. Although this prevalence is much lower than in our study, they observed a higher $\mathrm{PR}$ for women ( $\mathrm{PR}=1.39$; 95\%CI 1.12-1.72), and individuals performing re-entry tasks $(\mathrm{PR}=1.71 ; 95 \% \mathrm{CI} 1.33-2.20)^{8}$, which is consistent with our study. Another study with family farmers in Brazil reported a CMD prevalence of $27 \%$ for both genders, which is higher than for applicators but lower than for helpers in our study9.

A review found that a higher prevalence of mental health outcomes, notably depression, anxiety, and suicide attempts, were found positively associated with exposure to pesticide among farmers in high-income countries as the USA, England, South Korea, and Spain ${ }^{10}$. Depression was significantly associated with a history of pesticide poisoning, but not low or high cumulative exposure in spouses of pesticide applicators in the USA ${ }^{29}$.

The high variability of SRQ-20 can be explained by the questionnaire high sensitivity and capacity to identify a large spectrum of affections ${ }^{9}$, but also by biological and social factors (e.g. women tend to report more symptoms, and less educated individuals tend to over-report mental health complaints) ${ }^{14}$.

Previous studies conducted with Brazilian farmers indicated a scenario of exposure similar to our findings: low educational level and income, residential proximity to crop areas, working in crops since childhood, poor technical support and safety training, and lack or misuse of $\mathrm{PPE}^{16,18}$. Inadequate safety practices (e.g. drinking and eating at field and showering only at the end of workday) may increase pesticide exposure ${ }^{3,4}$. Moreover, poor understanding of pesticide instruction leaflets, and influence of neighbors on pesticide user's decisions, especially regarding handling and dosage, may compromise farmer's ability to reduce exposure and protect their health ${ }^{16}$.

In Brazil, complex mixtures of multiple pesticides are commonly sprayed by manual pumping or backpack tanks by smallholder family farmers ${ }^{16,17}$, which may result in potential additive and synergic effects, and greater health outcomes ${ }^{1,13}$. Pesticides are authorized for specific target-crops in Brazil, and the use of prohibited chemicals or those not allowed for tomato crops was observed in our study. Some pesticides banned or sale-restricted in other countries due to their high toxicity, such as Abamectin, Acephate, Glyphosate, and Paraquat, are still highly commercialized in Brazil ${ }^{13}$, and their use was mentioned in our study. Most symptoms found in our study were previously associated with OP pesticides exposure ${ }^{11}$, but the effects of pesticide mixtures cannot be ruled out and deserve further attention.

Major challenges on evaluating health effects of pesticide exposure among family farmers in Brazil are their widespread distribution, their continuous exposure to multiple chemicals, large distance of crop areas to health services, and the shortage of laboratories with analytical capacity ${ }^{13,17}$. According to the Brazilian law, all farmers must be periodically subjected to medical exams and cholinesterase tests, albeit this is not provided to millions of smallholder family farmers distributed in 4.4 million properties ${ }^{19}$. Cholinesterase enzymes are useful for screening of OP and CM poisoning or continuous monitoring, despite their high variability, and low sensitivity and specificity ${ }^{17}$. Measurements of urinary biomarkers are more suitable exposure assessment ${ }^{11}$, though expensive and seldom available in Brazil. In our study, applicators had more BChE inhibition and lower cholinesterase levels, which may indicate continuous exposures to high doses, avoiding a complete BChE recovery, but it contrasts with the fact that more symptoms had higher prevalence among helpers. 
Another study with Brazilian tomato farmers showed that $62 \%$ reported more than one illness after pesticide exposure, but only $21 \%$ of poisoned workers sought a health service and $70 \%$ self-medicated ${ }^{20}$. This low demand for health services, especially in less severe cases, compromises the visibility and hinders the understanding of the real dimension of the problem ${ }^{13}$.

The lack of an unexposed control group and the cross-sectional design were some limitations of this study. A longitudinal study with more sensible biomarkers would enable the evaluation of health effects over time and precisely associate them with exposure. Moreover, the convenience sampling and sample size of our study limit external validity. Thus, this study assumes an exploratory purpose, which only allows the assessment of associations but not cause-effect relationships, although indicating relevant hypotheses to be further investigated. Possible information and memory bias were minimized by an experienced health professional conducting the interviews, the access to recent symptoms, and trust relationships with participants. Moreover, our questionnaire was based on validated protocols, and pilot interviews ensured that the questionnaire was easily understood.

This investigation contributes to filling the data gap concerning occupational exposure to pesticides and health effects in Brazil by providing complementary evidence about family farmers, responsible for about $70 \%$ of food (mostly vegetables) consumed in the country ${ }^{13}$. This study highlights the demand for a more efficient technical support stimulating farmers to use chemicals consciously and better protect themselves. The strengthening of public policies that address the current vulnerability and risk of family farmers is urgent. Moreover, we strongly recommend a careful overhaul of the Brazilian legislation to restrict hazardous pesticides and encourage agricultural practices less dependent on pesticides for family farmers.

\section{CONCLUSIONS}

Our study indicates that Brazilian family farmers work without proper technical support and safety behavior that could reduce pesticide exposure and protect their health. Also, it highlights that public policies must target not only the applicators, but also other workers who often assist in crop activities and vulnerable groups both occupationally and environmentally exposed. The high exposure to pesticides must be a major public health concern because it reduces farmers' quality of life, affects the rural workforce, increases morbidity and mortality burden of diseases and health costs. Thus, we strongly recommend the strengthening of surveillance actions, technical support, and educational programs aiming at family farmers exposed to pesticides in Brazil. Promoting sustainable agriculture is the most effective way to protect farmers' health, general population, and the environment.

\section{REFERENCES}

1. Alavanja MCR. Pesticides use and exposure extensive worldwide. Rev Environ Health. 2009;24(4):303-9. https://doi.org/10.1515/reveh.2009.24.4.303

2. United Nations. Report of the Special Rapport on the Right to Food. Geneva: UN Human Rights Council; 2017 [cited 2020 Apr 6]. Available from: https://undocs.org/A/HRC/34/48

3. Manyilizu WB, Mdegela RH, Helleve A, Skjerve E, Kazwala R, Nonga H, et al. Self-reported symptoms and pesticide use among farm workers in Arusha, Northern Tanzania: a cross sectional study. Toxics. 2017;5(4):24. https://doi.org/10.3390/toxics5040024

4. Muñoz-Quezada MT, Lucero B, Iglesias V, Levy K, Muñoz MP, Achú E, et al. Exposure to organophosphate (OP) pesticides and health conditions in agricultural and nonagricultural workers from Maule, Chile. Int J Environ Health Res. 2017;27(1):82-93. https://doi.org/10.1080/09603123.2016.1268679 
5. Hutter HP, Kundi M, Lemmerer K, Poteser M, Weitensfelder L, Wallner P, et al. Subjective symptoms of male workers linked to occupational pesticide exposure on coffee plantations in the Jarabacoa Region, Dominican Republic. Int J Environ Res Public Health. 2018;15(10):2099. https://doi.org/10.3390/ijerph15102099

6. Negatu B, Vermeulen R, Mekonnen Y, Kromhout H. Neurobehavioural symptoms and acute pesticide poisoning: a cross-sectional study among male pesticide applicators selected from three commercial farming systems in Ethiopia. Occup Environ Med. 2018;75(4):283-9. https://doi.org/10.1136/oemed-2017-104538

7. Poletto AR, Gontijo LA. Family farming workers mental health in a microrregion in southern Brazil. Work. 2012;41 Suppl 1:4987-94. https://doi.org/10.3233/WOR-2012-0044-4987

8. Faria NMX, Fassa AG, Meucci RD, Fiori NS, Miranda VI. Occupational exposure to pesticides, nicotine and minor psychiatric disorders among tobacco farmers in southern Brazil. Neurotoxicology. 2014;45:347-54. https://doi.org/10.1016/j.neuro.2014.05.002

9. Campos Y, Silva VSP, Mello MSC, Otero UB. Exposure to pesticides and mental disorders in a rural population in Southern Brazil. Neurotoxicology. 2016;56:7-16. https://doi.org/10.1016/j.neuro.2016.06.002

10. Khan N, Kennedy A, Cotton J, Brumby S. A pest to mental health? Exploring the link between exposure to agrichemicals in farmers and mental health. Int J Environ Res Public Health. 2019;16(8):1327. https://doi.org/10.3390/ijerph16081327

11. Muñoz-Quezada MT, Lucero BA, Iglesias VP, Muñoz MP, Cornejo CA, Achu E, et al. Chronic exposure to organophosphate (OP) pesticides and neuropsychological functioning in farm workers: a review. Int J Occup Environ Health. 2016;22(1):68-79. https://doi.org/10.1080/10773525.2015.1123848

12. Fundação Oswaldo Cruz, Instituto de Comunicação e Informação Científica e Tecnológica em Saúde. SINITOX - Sistema Nacional de Informações Tóxico-Farmacológicas: dados nacionais de intoxicação. Rio de Janeiro; ICICT; 2018 [cited 2018 Jun 14]. Available from: https://sinitox.icict. fiocruz.br/dados-nacionais

13. Carneiro FF, Augusto LGS, Rigotto RM, Friedrich K, Búrigo AC, organizadores. Dossiê ABRASCO: um alerta sobre os impactos dos agrotóxicos na saúde. Rio de Janeiro: Escola Politécnica de Saúde Joaquim Venâncio; 2015 [cited 2020 Apr 6]. Available from: https://www.abrasco.org.br/ dossieagrotoxicos/wp-content/uploads/2013/10/DossieAbrasco_2015_web.pdf

14. Carmo MBB, Santos LM, Feitosa CA, Fiaccone RL, Silva NB, Santos DN, et al. Screening for common mental disorders using the SRQ-20 in Brazil: what are the alternative strategies for analysis? Braz J Psychiatry. 2018;40(2):115-22. https://doi.org/10.1590/1516-4446-2016-2139

15. World Health Organization. Depression and other common mental disorders: global health estimates. Geneva: WHO; 2017 [cited 2020 Apr 6]. Available from: http://apps.who.int/iris/ bitstream/10665/254610/1/WHO-MSD-MER-2017.2-eng.pdf

16. Pedlowski MA, Canela MC, Terra MAC, Faria RMR. Modes of pesticides utilization by Brazilian smallholders and their implications for human health and the environment. Crop Prot. 2012;31(1):113-8. https://doi.org/10.1016/j.cropro.2011.10.002

17. Bendetti D, Alves J, Silva FRD, Silva JD. An evaluation of occupational exposures to pesticides in Brazil. Occup Med Health Aff. 2014;2:170. https://doi.org/10.4172/2329-6879.1000170

18. Lermen J, Bernieri T, Rodrigues IS, Suyenaga ES, Ardenghi PG. Pesticide exposure and health conditions among orange growers in Southern Brazil. J Environ Sci Health B. 2018;53(4):215-21. https://doi.org/10.1080/03601234.2017.1421823

19. Instituto Brasileiro de Geografia e Estatística. Censo Agro 2017. Rio de Janeiro: IBGE; 2017 [cited 2020 Apr 6]. Available from: https://censos.ibge.gov.br/agro/2017/

20. Delgado IF, Paumgartten FJR. Intoxicações e uso de pesticidas por agricultores do Município de Paty do Alferes, Rio de Janeiro, Brasil. Cad Saude Publica. 2004;20(1):180-6. https://doi.org/10.1590/S0102-311X2004000100034

21. Leão RS, Marques RC, Buralli RJ, Silva DS, Guimarães JRD. Avaliação de saúde pública por exposição a agroquímicos: uma experiência com a agricultura familiar no noroeste do Rio de Janeiro. Sustentabil Debate. 2018;9(1):81-94. https://doi.org/10.18472/SustDeb.v9n1.2018.26956

22. Buralli RJ, Ribeiro H, Mauad T, Amato-Lourenço LF, Salge JM, Diaz-Quijano FA, et al. Respiratory condition of family farmers exposed to pesticides in the state of Rio de Janeiro, Brazil. Int J Environ Res Public Health. 2018;156(6):1203. https://doi.org/10.3390/ijerph15061203 
23. Oliveira-Silva JJ, Alves SR, Inacio AF, Meyer A, Sarcinelli PN, Mattos RC, et al. Cholinesterase activities determination in frozen blood samples: an improvement to the occupational monitoring in developing countries. Hum Exp Toxicol. 2000;19(3):173-7. https://doi.org/10.1191/096032700678827762

24. Santos KOB, Carvalho FM, Araújo TM. Internal consistency of the self-reporting questionnaire-20 in occupational groups. Rev Saude Publica. 2016;50:6. https://doi.org/10.1590/S1518-8787.2016050006100

25. Mari J, Williams P. A validity study of a psychiatric screening questionnaire (SRQ-20) in primary care in the city of Sao Paulo. Br J Psychiatry. 1986;148:23-6. https://doi.org/10.1192/bjp.148.1.23

26. Ministério da Saúde (BR), Secretaria de Vigilância Sanitária. Portaria No 3, de 16 de Janeiro de 1992. Brasília, DF; 1992 [cited 2018 May 25]. Available from: http://bvsms.saude.gov.br/bvs/ saudelegis/svs1/1992/prt0003_16_01_1992.html

27. Silva M, Stadlinger N, Mmochi AJ, Lundborg CS, Marrone G. Pesticide use and selfreported health symptoms among rice farmers in Zanzibar. J Agromed. 2016;21(4):335-44. https://doi.org/10.1080/1059924X.2016.1211572

28. Thundiyil JG, Stober J, Besbelli N, Pronczuk J. Acute pesticide poisoning: a proposed classification tool. Bull World Health Organ. 2008;86(3):205-9. https://doi.org/10.2471/BLT.08.041814

29. Beseler C, Stallones L, Hoppin JA, Alavanja MCR, Blair A, Keefe T, et al. Depression and pesticide exposures in female spouses of licensed pesticide applicators in the Agricultural Health Study cohort. J Occup Environ Med. 2006;48(10):1005-13. https://doi.org/10.1097/01.jom.0000235938.70212.dd

Funding: This research was funded by the Brazilian Conselho Nacional de Desenvolvimento Cientifico e Tecnológico (CNPq) through the project Universal 479364/2012-5. Rafael Buralli was funded by the Coordenação de Aperfeiçoamento de Pessoal de Nivel Superior (Capes) and had a great support from the Internationalization Project UCH 1566 - Universidad de Chile. Helena Ribeiro is funded by CNPq.

Authors' Contribution: Concepção e planejamento do estudo: RJB, HR, RSL, RCM, JRDG. Coleta, análise e interpretação dos dados: RJB, HR, VI, MTMQ, RSL, RCM, MMCA, JRDG. Elaboração ou revisão do manuscrito: RJB, HR, VI, MTMQ, RSL, RCM, MMCA, JRDG. Aprovação da versão final: RJB, HR, VI, MTMQ, RSL, RCM, MMCA, JRDG. Responsabilidade pública pelo conteúdo do artigo: RJB, HR, VI, MTMQ, RSL, RCM, MMCA, JRDG.

Conflict of Interest: The authors declare no conflict of interest. 